\title{
Editorial
}

\section{WHAT USEFUL ON ANATOMY EDUCATION GIVE US THE PANDEMIC?}

\author{
Konstantinos Natsis \\ Department of Anatomy and Surgical Anatomy, School of Medicine, Faculty of Health \\ Sciences, Aristotle University of Thessaloniki, Greece
}

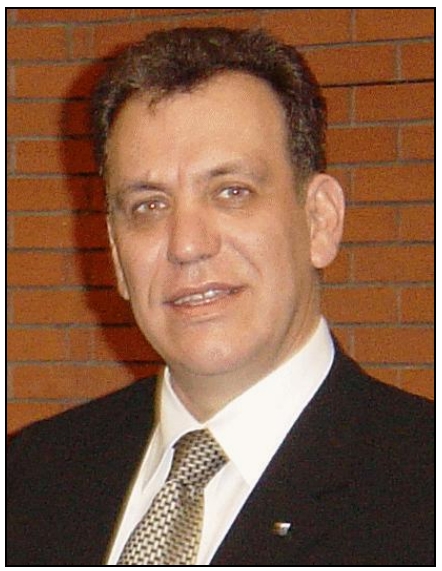

The COVID-19 pandemic outbreak was followed by the imposition of restrictive measures, resulting in the suspension of the Universities, worldwide. Remote medical education has developed as the only available option (Singal et al. 2020a). In Anatomy, it is practically impossible to substitute the gold standard teaching method, for over four centuries, (Singal et al. 2020b), the cadavers' dissection (Ooi and Ooi, 2020; Ortadeveci et al. 2021). In Greece, the Anatomy and Surgical Anatomy Department of the Medical School of the Aristotle University of Thessaloniki (AUTh) substituted the "face to face" cadavers' dissection courses with online cadavers' dissection videos courses after taking into consideration the auxiliary role of the videos used in anatomy learning (in students' interaction and active engagement) (Topping, 2014; ChoiLundberg et al. 2016; Singal et al. 2020a). The teaching novelty is mainly focused on the live presentation of cadavers' dissection videos with comments and chatting with students on the dissection findings. All videos with the recorded narration and discussion were available to download, in an effort to give students the opportunity to become familiar with the cadavers' dissection steps (Fig.1). An online questionnairebased study was performed in the Anatomy and Surgical Anatomy Department of AUTh, focusing on the impact of pandemic in anatomy education. The vast majority of students supported that the cancel-lation of cadavers' dissection labs negatively affected their education. Students' responses provided the necessity of the presentation of a cadaveric dissection video with a detailed description of the dissected structures, even after the end of the pandemic and the restart of the "face to face" cadavers' dissection courses, as supplementary material of the on-site cadavers' dissection lectures (Fig.2). Several authors (Estai and Bunt, 2016; Wenger and Berray, 2006; Ghosh, 2017) highlighted the students' preference for an interactive teaching and learning based on a synchronous narration of a cadaveric dissection video with real time dialogue and students' active engagement in the learning procedure. Ozer et al. (2017) similarly to Langfeld et al. (2018) concluded that the videoassisted students' learning increased the selfmotivation, via the videos accessibility at any time. Cadavers' dissection remains the most preferred and effective teaching modality. Given its paramount importance in anatomy education, a new modality is proposed with the cadavers' dissection videos use, as an alternative teaching tool to the cadavers' dissection laboratory practice (Styers et al. 2018; Nation et al. 2020). The new modality will help the better comprehension of the dissected structures, particularly in complex areas, and the active learning during the cadavers' dissection process. 


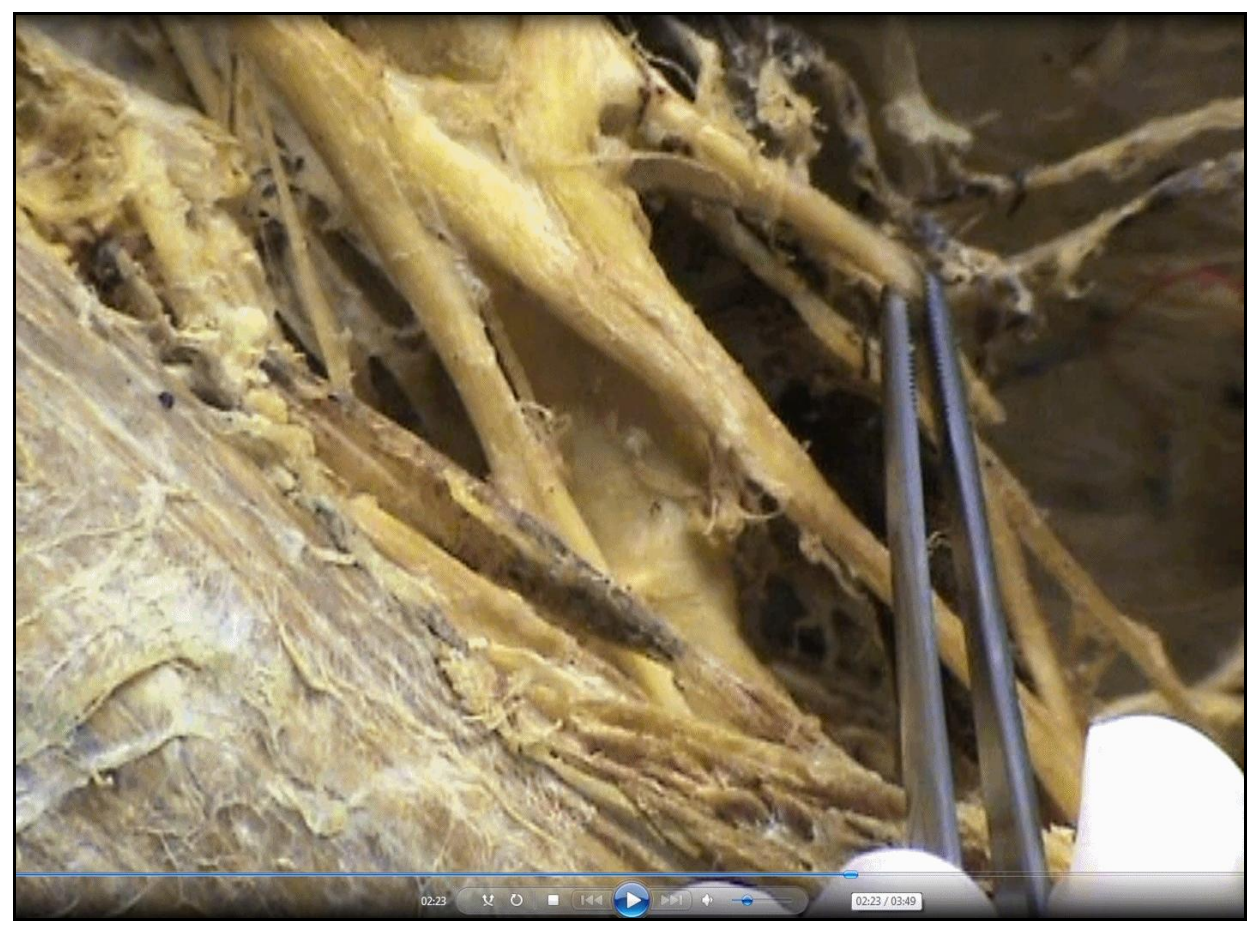

Figure 1. Print screen from a cadaver's dissection video depicting the brachial plexus overview in the area of the ending nerves formation (formation of the characteristic letter $\mathrm{M}$ ). The anatomic tong shows the ulnar nerve

\section{Past-Pre-pandemic:}

Theory: Pre-dissection courses (auditorium lectures) with cadaveric images

Practice: "Face to face" cadavers' dissection (lab)

\section{During Pandemic:}

Theory: Online lectures with cadaveric images Practice: Online cadavers' dissection videos

\section{Future Perspective-Proposal:}

Theory: Lectures with cadaveric images and dissection videos

Practice: Face to face cadavers' dissection (lab)

Figure 2. Schematic representation of the philosophy of genesis of the new teaching modality of cadavers' dissection videos, essential in laboratory practice, regardless of time period

In conclusion, COVID-19 pandemic created the need for novel teaching modalities, particularly in the cadavers' dissection process. Undoubtedly, cadavers' dissection is irreplaceable. The editorial highlights the supplementary online use of the cadavers' dissection videos, as a new modality to assist the cadavers' dissection training. The proposed teaching tool should be further developed in order to become a sustainable way of assisting cadavers' dissection by enhancing the involvement of both teaching staff and students.

\section{REFERENCES}

Choi-Lundberg DL, Cuellar WA, Williams AM. 2016. Online dissection audiovisual resources for human anatomy: Undergraduate medical students' usage and learning outcomes. AnatSciEduc 9: 545-54

Estai M, Bunt S. 2016. Best teaching practices in anatomy education: A critical review. Ann Anat 208: 151-57. doi: 10.1016/j.aanat.2016.02.010.

Ghosh SK. 2017. Cadaveric dissection as an educational tool for anatomical sciences in the 21st century. Anat Sci Educ 10: 286-99

Langfeld T, Colthorpe K, Ainscough L. 2018. Online instructional anatomy videos: student usage, self-eficacy, and performance in upper limb regional anatomy assessment. AnatSciEduc 11:461-470

Nation H, Kaliski D, Ortiz A. 2020. Narrated Dissection Videos and Peer-Mentoring to Enhance Anatomy Performance of Underrepresented Minority Students in Physical Therapy Education. Anat Sci Educ. (in press; doi: 10.1002/ase.1971) 
Ooi SZY, Ooi R. 2020. Impact of SARS-CoV-2 virus pandemic on the future of cadaveric dissection anatomical teaching. Med Educ Online 25: 1823089

Ortadeveci, A., Ermez, M.N., Oz, S. 2021. A survey study on distance anatomy education: challenges unique to anatomy. Surg Radiol Anat, https://doi.org/10.1007/s00276-02102772-z

Ozer MA, Govsa F, Bati AH. 2017. Web-based teaching video packages on anatomical education. SurgRadiolAnat 39:1253-61

Singal A, Bansal A, Chaudhary $P$, Singh $H$, Patra A. 2020a. Anatomy education of medical and dental students during COVID-19 pandemic: a reality check. Surg Radiol Anat 43: 515-21.
Singal A, Bansal A, Chaudhary P. 2020b. Cadaverless anatomy: Darkness in the times of pandemic Covid-19. Morphologie 104(346):14750.

Styers ML, Van Zandt PA, Hayden KL. 2018. Active Learning in Flipped Life Science Courses Promotes Development of Critical Thinking Skills. CBE Life Sci Educ 17: ar39

Topping DB. 2014. Gross anatomy videos: student satisfaction, usage, and effect on student performance in a condensed curriculum. Anat Sci Educ 7: 273-79.

Wenger C, Berray SJ. 2006. Anatomy in a new curriculum: Facilitating the learning of gross anatomy using web access streaming dissection videos. J Vis Commun Med 29: 99108 